\title{
FILOSOFIAS DE LA HISTORIA: ¿POR QUÉ Y PARA QUIÉN? `
}

\author{
por \\ GONZALO BRAVO \\ Universidad Complutense
}

\section{PRESENTACIÓN}

«Por filosofía de la historia se ha entendido hasta ahora una de estas dos cosas: o el intento de construir el contenido de la historia mediante categorías sensu stricto filosoficas (Hegel), o bien la reflexión sobre la forma intelectual que la historiografía practica (Rickert). Esta es una lógica, aquella una metafísica de la historia (Benavides, 551). Aunque estas palabras del autor (en adelante A.) de Filosofia de la Historia (en adelante $\mathrm{FdH}$ ) pretenden resumir un discurso, cuando menos centenario, resulta difícil ver qué tienen de común ambas formas con lo que los historiadores hacen habitualmente, es decir, con la historiografía. Naturalmente, el oficio del filosofo incluye, entre otros, la teorización que, como tal, no tiene más límites que no perder del todo de vista al objeto ni caer en el análisis histórico, propiamente dicho; esto es, construyendo el discurso -en este caso filos6fico- con ideas, no con hechos. Por esta razón y ante obras como la presente uno puede justamente preguntarse por qué se ha elaborado un manual de estas características y, ante todo, para quién o a quiénes va dirigido. Porque, digámoslo ya, un libro así no se improvisa; al contrario, es fruto de un largo proceso de maduración, cualquiera que sea la formación y experiencia del A. Dicho de otro modo, el recorrido analítico por veinticinco siglos de historia - más que de historiografía- requiere una sistemática conceptual y teorética poco común, al menos en los ámbitos bibliograficos por los que suele transitar el historiador. Cabe preguntarse, finalmente, hasta qué punto los historiadores consideran o no útiles para sus investigaciones libros como éste. Porque, generalmente, a un historiador de oficio no le resulta fácil teorizar acerca de su propio trabajo, razón por la cual durante generaciones fueron los filósofos - 0 algunos filósofos, para ser más exactos-quienes reflexionaron acerca de la naturaleza, método y formas de

1 M. Benavides Lucas, M., Filosofia de la Historia, Ed. Sintesis, Madrid 1994, ISBN: 84 7738-240-9, 701 págs. 
hacer la historia. Pero hoy quizá estemos ya en condiciones de dudar si la reflexión teórica es suficiente, si los historiadores (de oficio) no deberfan aportar su experiencia al debate sobre las «filosofías» de la historia, si, en definitiva, podemos seguir asumiendo la separación entre teoría y praxis en términos tales que sea posible teorizar sobre un objeto sin un conocimiento práctico y preciso del mismo, de sus posibilidades tanto como de sus limitaciones.

\section{DISCIPLINA Y AMBITO}

Como es sabido, la filosofía de la historia es tanto una disciplina academica como un ámbito térico de indudable interés para quienes de una forma $u$ otra tienen relacion con la historia. En ambas acepciones, sin embargo, esta rama de la filosofía y/o de la historia es objeto de una peculiar paradoja. Como disciplina, ha sido tradicionalmente relegada - si no marginada - de los sucesivos planes de estudios universitarios de las Licenciaturas de Historia, laguna que hasta ahora cubría difícilmente una materia tan amplia y vaga como la denominada Teoria y método de la historia - todavía vigente- y aún menos la de Métodos y técnicas de investigación histórica, de inminente implantación. Por otro lado, como ámbito térico, debería ser de obligada atención no sólo para los estudiantes universitarios, sino también para los profesionales de la historia de los diversos niveles educativos, en cuanto marco de referencia al que remiten casi todas las interpretaciones históricas. Pero la falta de tradición y - salvo excepción - una acusada deficiencia formativa -en términos teóricos- de nuestras escuelas historiográficas han hecho que la filosoffa de la historia —o la teoria, si se prefiere- no sean más que un mero desideratum para muchos historiadores de oficio, bien porque no se sienten atraídos por la gnoseología del saber que practican, bien porque no se sienten interesados en conocer la evolución del concepto «historia más allá del campo al que generalmente se adscriben. En cualquier caso, estos historiadores, apegados al análisis de situaciones concretas, simplemente no se sienten atrádos por este tipo de lecturas, que consideran un mero ejercicio especulativo, propio de los filosofos, aunque versen sobre la naturaleza de la historia. Unos y otros entienden que la historia, en tanto que actividad escrita -esto es, historiografia - no es susceptible de teorizaciones sino en todo caso de teorías, y aun éstas formuladas solo por quienes la practican. Naturalmente, además de estas dos posiciones hay otras menos definidas, más ambiguas, cuyos discursos respectivos (filosófico e histórico) replantean la cuestión de en qué medida podría establecerse la línea divisoria entre dos formas de conocimiento que, como en este caso, resultan ser mutuamente complementarias. En efecto, la filosofía de la historia lleva implicada en sus posibles variantes (de hecho, filosofías de lo histórico) el conocimiento del concepto y el análisis de su evolución en las distintas corrientes o escuelas de pensamiento, pero también la reflexión sobre la práctica historiográfica, sobre lo que hoy se postula como las diversas formas

Hispania, LVI/2, núm. 193 (1996) 757-763 
de hacer historia (Cfr. P. Burke (ed.), Formas de hacer Historia, Alianza Edit., Madrid, 1993, no citado por el A.). En este sentido, un historiador puede ignorar las metafísicas o las metateorias, pero debe conocer de alguna manera la lógica del conocimiento histórico, aunque sólo sea para evitar las falacias en que suelen caer algunos historiadores ( $C$ fr. D. H. Fischer, Historian's Fallacies. Toward a Logic of historical Thought, Londres, 1970, y G. Bravo, "Sobre el uso y validez e los modelos en Historia: posibilidades y limitaciones», en III Congreso de Teorta y Metodología de las Ciencias, Oviedo, 1988, págs. 699-710).

\section{PARTES O FILOSOFtas dE LA HISTORIA}

La $F d H$ de Benavides proporciona un completo dossier de referencias conceptuales, analíticas y críticas, de indudable interés para los historiadores a pesar de su a menudo farragosa presentación. Pero uno pronto se percata de que la complejidad del mensaje apenas permitirfa un tratamiento más simple sin sacrificar parte de su contenido. Digamos que, en principio, el único elemento disuasorio del discurso de Benavides es el continente: casi un centenar de autores (filósofos e historiadores) tienen epígrafe en el Índice, pero muchos más son mencionados a título comparativo en el texto, como veremos después, y setecientas páginas de discusión teorética exigen una predisposición más que común para la lectura.

Aun a sabiendas de que, ni siquiera en filosofía de la historia, la divisoria entre las distintas "filosofias" puede ser establecida con certidumbre, el A. estructura la $F d H$ en tres partes (especulativa, critica y analitica), en gran medida consecutivas, porque es la evolución cronológica -y no la problemática- el criterio seguido por Benavides como hilo conductor de su multiforme discurso: desde Hesíodo, a comienzos del siglo vi a. de C., en Grecia, hasta la obra de K. Popper, Gadamer o P. Veyne, en nuestros días. Sin duda que el criterio cronológico es tan válido como cualquier otro, pero acarrea algunas servidumbres como, por ejemplo, que la primera parte de la $F d H$ parezca, de hecho, más una historia de la filosofía que una filosofía de la historia o simplemente una filosofía, temor que el propio A. trasmite al lector en varias ocasiones: "la historia de la filosofía es... una disciplina interna a la filosofta..., cuando se hace auténtica historia de la filosofía, se hace filosofía" (FdH, 547), o "una filosofía de la historia no puede aislarse de otras ramas de la filosofia" (FdH, 597). Resulta inevitable, entonces, que las "partes» se conviertan de hecho en etapas correlativas a la evolución de la historia del pensamiento.

En efecto, la filosofía especulativa (etapa también llamada filosofías sustantivas, siguiendo la denominación de Danto) abarca casi la mitad de la obra, desde los griegos hasta Hegel, a comienzos del siglo XIX y, sin embargo, estas filosofías son las que menos interesan hoy a los historiadores desde la perspectiva de utilidad del conocimiento, porque en general los problemas se plantean aquí en términos propiamente idealistas o, si se prefiere, metafísi- 
cos, como si los hechos históricos fueran meras manifestaciones de designios divinos (Agustín) o, por el contrario, simples constructos mentales de la realidad «sin formas (Kant).

Siempre desde la perspectiva del historiador, más interesante resulta, en cambio, la segunda parte, denominada ala filosofía crítica», que grosso modo viene a corresponder al historicismo del siglo XIX alemán, de un lado, desde la «razón de Estado" de Hegel a la "muerte de Dios» de Nietzsche (Cfr., por ejemplo, J. C. Bermejo, "Friedrich Nietzsche: la moral y la Historia", en El final de la historia. Ensayos de historia teorica, Ed. Akal, Madrid, 1987, págs. 227 ss.; espec. 253-255), y de otro lado, a las ramificaciones del pensamiento europeo, desde Marx-Engels a Spengler, Ortega e incluso Popper. Más que una metafísica, estas filosoffas de la historia son ante todo una logica del conocimiento histórico, que incluye a filósofos e historiadores tan dispares como el ilustrado Herder, el positivista Ranke o el idealista Weber, sin olvidar a Dilthey, Rickert y Simmel, todos ellos reseñados en sendos capítulos. Pero la crítica sistemática del historicismo es obra conjunta de Nietzsche, Marx y Popper. Según Nietzsche, si el historiador pretende romper con el pasado - para superarlo- o mejor «con el espejo del pasado» $(F d H, 450)$ debe elaborar una historia crítica, sin veneracion por los hechos, pero tampoco sin olvidar las perversiones del pasado; por su parte, Marx sostiene que lo que debe superarse es la visión idealista hegeliana de la historia sustituyéndola por una visión materialista, desde la que es posible proponer una explicación científica de la historia; en fin, Popper, acaso erróneamente, critica la pretensión de quienes sostienen que la historia se explica mediante leyes generales, como las ciencias físicas o naturales, y que tiene capacidad predictiva.

Por fin, la tercera parte o filosofia analítica es la corriente predominante en nuestros días, que basa sus reflexiones sobre ael significado y verdad de las proposiciones históricas; sobre la posibilidad de la objetividad en historia; sobre la explicación, la causalidad histórica y los valores" (FdH, 597) o, más concretamente: el idealismo anglosajón, desde Collingwood a Oakeshott; el modelo nomológico, desde Hempel a von Wright; la historia narrativa, desde Danto a P. Veyne; en fin, la historicidad, de Heidegger a Gadamer, entre otros, son algunos de los temas tratados en esta última parte de la obra, sin duda la más interesante para los historiadores, pero también -en nuestra opiniónexcesivamente resumida (téngase en cuenta que toda esta tercera parte ocupa un espacio similar al dedicado en la $F d H$ a Kant y Hegel (capitulos 11 y 12, y 13 y 14, respectivamente). La obra se completa mediante un primer capitulo referido al sentido de la historia que, aun incluido en la filosofía especulativa, supera claramente el marco cronológico atribuido en la $F d H$ a esta etapa, proyectándose incluso hasta el momento presente en la obra de Popper, Veyne, P. Vilar y, ante todo, $K$. Löwith y $R$. Aron, y se cierra con una copiosa bibliografía, en la que apenas faltan nombres, si acaso algunos historiadores-filósofos con producción abundante y reconocida en este campo, como J. C. Bermejo (ahora también con Entre Historia y Filosofia, Madrid, 1994), P. Burke, Berkhoffer, Fischer, Coteau-Begarie, Thompson, entre otros.

Hispania, LVI/2, num. 193 (1996) 757-763 


\section{ALGUNOS EJEMPLOS}

Tan sólo algunos ejemplos serán suficientes para ilustrar la forma y contenido de algunos de los muchos temas aquí tratados. Renunciando por razones obvias a plantear una batería de cuestiones puntuales, digamos, en principio, que el A. minusvalora claramente la aportación de las filosofías especulativas de la historia, de las que llega a dudar si «tienen, aparte de su nulo valor cognoscitivo, algún otro alcance» ( $F d H$, pág. 36 ), a pesar de que pretenden ser «una interpretacion sistemática de la historia universaln. Pero afirmaciones así, sin las pertinentes matizaciones o excepciones, suelen volverse contra uno mismo, porque pueden aplicarse a filosofías tan dispares como el «agustinismo* y el amarxismo». Como es sabido, el marxismo o, mejor dicho, el materialismo histórico se postula como una interpretación de este tipo y, sin embargo, no forma parte -y justamente- de las filosofías especulativas sino en todo caso críticas de la historia. Pero Benavides, tras un atinado análisis del universo térico en que opera el marxismo, concluye que tampoco éste «ofreció una respuesta coherente al problema de las relaciones entre la estructura y el sujeto en la sociedad y la historia humana» (ibfd., pág. 470), es decir, no mucho más que el sistema del "civitate dei» del obispo de Hipona, a comienzos del siglo v. Pero mientras que la concepción cristiana de la historia no fue, de hecho, una "filosofía" (de la historia), el marxismo, en cualquiera de sus acepciones (materialismo dialéctico, materialismo histórico), sí.

Otra cuestión global, que implica a antiguos y modernos, filosofó e historiadores, es la determinación del sentido de la historia, sobre el que, en palabras de Benavides, sversa la filosofía de la historia» ( $F d H$, pág. 46), invocando incluso el testimonio de historiadores marxistas como P. Vilar, para quien el sentido es ula condición de la ciencia histórica" como tal. Pero naturalmente esta "condición" está muy lejos de la acepción metafísica de «sentido" en la obra de Löwith e incluso de ser una "dimensión" de la conciencia histórica, propugnada por $\mathbf{R}$. Aron, porque no se trata de un «fin trascendente" sino inmerso en el propio devenir histórico, que no se expresa propiamente como "fin», sino que se materializa a menudo como «cambio». Quizás el ejemplo más claro, entre los filosofos, de que «la vida cambias lo proporciona la «teoría de las generacionesn de Ortega, a quien Benavides dedica un magistral y detenido análisis; pensaba el insigne filossofo español que "cada quince años" la estructura de la vida se transformaba, que cada generacion aportaba a la vida una nueva sensibilidad para pensar y sentir. Pero Ortega creía en el individuo y no en el colectivo, por lo que es objeto de una dura crítica por parte del A.: [Ortega] parece olvidar que ese tiempo [tiempo de las generaciones] es, como tiempo histórico propiamente tal un tiempo cualitativo, hecho de intensidades y laxitudes, y también es un tiempo colectivo, compartido; en una palabra, social, y solo en cuanto tal se puede ofrecer a la historiografian FdH, pág. 563). Tal crítica no es, sin embargo, gratuita, sino precisamente el resultado de un singular estudio comparativo de la posición orteguiana en relación con 
el universo de influencias filosóficas, historiográficas y cientificas que recibe el autor ${ }^{2}$ : Meier-Grefe, Baroja, Azorín, Hegel (12), Spengler (2), Marx (2), Descartes (3), Bachofen, Huizinga, Denis de Rougemont, Cassirer, Plessner (2), Krieger, Dilthey (7), Croce (2), Von Vexküll (3), Jennings, Spranger, Focillon, Rousseau, Simmel, Mann, Hesse, Frobenius (2), Rickert (5), Husserl (5), Scheler (2), Febvre, Kant (2), Duhem, Brehier (2), Voländer, Heidegger (2), Cornford Foucault (2), Kuhn, Taine, Buckle, Ratzel, Chamberlain, Ibn Jaldún, Niebuhr, Goethe (2), Aristoteles, Droysen, Windelband, Heráclito, Ranke (2), Franklin, Weber (2), Köhler, Driesch, Gehlen, San Agustín, Leibniz, Hamilton, Toynbee, Mommsen, Meyer y Delbruick.

Finalmente, ya en el campo de la filosofía analítica (de la historia), de forma recurrente se plantea la cuestión de como definir el objeto -mejor objetividad- de la historia y la especificidad del conocimiento histórico respecto del pasado y del presente. En este sentido, Benavides se adscribe claramente a las tesis del idealismo historicista de un Collingwood (stoda historia es la historia del pensamienton) o de un Walsh (*la historia consiste en el repensamiento de los pensamientos pasados») e incluso de un Croce («toda historia es historia contemporánean) cuando afirma - sin desperdicio- lo siguiente: «la historia no es conocimiento del pasado y, en consecuencia, desconocimiento del presente; tampoco es conocimiento del presente y, en consecuencia, desconocimiento del pasado, sino que es conocimiento del pasado en el presente, que no es otro que el autoconocimiento de la mente del historiador en cuanto reactualización y revivificacion presente de experiencias pasadas" (FdH, pág. 586). Es decir, desde este punto de vista, la objetividad de la historia 0 , mejor dicho, de la historiografía no es sino un mero desideratum de algunos historiadores, no importa si positivistas (que la ven en los documentos) o marxistas (en la transformación de la sociedad).

\section{ALGUNAS CUESTIONES}

Se comprende ahora por qué, al principio, dudábamos acerca de si la elaboración de un estudio sobre filosofias de la historia, como ámbito térico, requeriría no sólo un adecuado conocimiento de la afilosofía de la ciencia» como disciplina sino también la experiencia de la práctica historiográfica. El propio A. alude a este problema cuando llega a afirmar que ula epistemología de la historia no tiene por qué ser un asunto exclusivo de los filosofos, analiticos o non (ibtd. pág. 598) porque por encima de la especulación del filosofo y el rigor del historiador está el valor de la experiencia del «historiador de oficion, experiencia que permite - y a menudo exige- plantearse también cuestiones epistemológicas como, en su día, lo hicieron Ranke, Droysen,

${ }^{2}$ A modo de ejemplo proporcionamos un listado de las referencias de autores citados por Benavides - a propósito de las teorías de Ortega - siguiendo el orden de su primera mención e incluyendo entre paréntesis - si procede- el número de referencias del autor en contextos temáticos distintos, pero dentro del mismo capítulo.

Hispaniá, LVI2, núm. 193 (1996) 757-763 
Burkhardt, Febvre, Bloch, Marrou, Carr, Braudel, Veyne, Le Goff y P. Vilar, entre otros. De ese diálogo -añade- no se pueden esperar "más que beneficios para ese saber normativa y éticamente orientado que es el conocimiento del pasadow. Pero los historiadores no suelen identificarse en este tipo de proclamas y, en cambio, tienen claro hoy que su lugar se encuentra en una de estas dos tendencias: la de quienes consideran con Bury que «la historia es una ciencia, nada menos ni nada más», con independencia de si se trata de una ciencia natural (historicistas), humana (positivista), social (marxistas) o «sui generis» (neopositivistas), que se rige por «leyes" conforme al modelo nomológico (Hempel) y que su objetivo es la explicación del pasado (von Wright); o bien, la de quienes con Veyne consideran que «la historia no es ciencia en absoluto", que no explica nada, porque no busca ya «leyes», sino tampoco «generalizaciones», y que su objetivo es simplemente narrativo, puesto que el discurso histórico consiste básicamente en la «retrodicción», es decir whacer hablar al pasado" o simplemente describir y comprender por empatía el «paisaje vital» del que hablaba Ortega.

En definitiva el conocimiento de las filosofias de la historia debería ser un marco teorico de referencia para los historiadores de oficio y no una amenaza clasificatoria, en virtud de la cual uno podría ser condenado por especulativo, por crítico o incluso por analítico, si no por anacrónico, historicista, ecléctico o cosas similares. Si la historiografía, propiamente dicha, incluye también las aportaciones de la reflexión teórica es porque el discurso histórico no se limita a «lo que ha sucedido", ni siquiera a "como sucedí6 realmente" (el «wie es eigentlich gewesen" de Ranke), sino tambien a «la narración de lo que ha sucedidon, que conlleva una buena dosis de interpretación y valoracion. Cabe preguntarse, entonces, si no hubiera sido más útil y claro - al menos, para los historiadores- el desarrollo del rico contenido de la obra mediante una serie de estudios monográficos al estilo anglosajón (prácticamente solo aplicado en la tercera parte) en vez de presentar la historia de las ideas sobre la historia de forma secuencial y, en muchas ocasiones, biografica.

No obstante, esta $F d H$, supla o no las deficiencias formales acusadas en la práctica historiográfica ordinaria, está destinada a tener larga vida, porque proporciona a filósofos e historiadores o, mejor, a los estudiantes de ambas disciplinas académicas, un completo dossier de referencias textuales y teoréticas difícilmente accesibles por los propios medios, un auténtico tratado y casi un diccionario de filosofía e historiografía, lo que supone un notorio esfuerzo de recopilación, sistematización y reflexión, que hará además reflexionar a no pocos historiadores, si logran culminar su lectura. Empresas como ésta son poco frecuentes, pero suelen merecer la pena. 